\title{
Supplemental Information Appendix
}

\section{SI Appendix Methods}

\section{In vitro Glucose Stimulated Insulin secretion (GSIS)}

For in vitro GSIS studies, mouse islets were harvested at 4wks of age. 15 IEQs were hand-picked and cultured in 24-well plates with $1 \mathrm{~mL}$ KREBS buffer + low glucose $(2.2 \mathrm{mM})$ for $30 \mathrm{~min}$, followed by $1 \mathrm{~mL}$ KREBS + high glucose $(22.2 \mathrm{mM})$ for $30 \mathrm{~min}$, and finally $1 \mathrm{~mL} 5 \% \mathrm{v} / \mathrm{v}$ acid-ethanol (to assess total insulin content) and frozen at -20C overnight. After each step, media/acid-ethanol was harvested for insulin assay.

\section{In vivo $\beta$-cell proliferation}

$\beta$-cell proliferation was quantified as percentage of Ki67-insulin to total insulin-positive cells on pancreatic sections stained with antibodies against insulin and Ki67 (ThermoFisher Scientific, Waltham MA; \#RM-9106-S1), using Alexa Fluor 488 anti-guinea pig and Alexa Fluor 594 antirabbit (Life Technologies, Carlsbad CA; \#A11073 and \# A11037, respectively) as secondary antibodies.

\section{SI Appendix Figure Legends}

Supplemental Figure 1. Experimental design and characterization of F1 progeny from RIP-mPL1/ Akita and RIP-Cre/Akita breeding. A) Genotypes and experimental design of the RIP-mPL1/Akita and RIP-Cre/Akita mouse models. Weekly body weight of WT (black), PL (green), Ak (blue), and PL-Ak (red) mice in B) males ( $\mathrm{n}=8-13$ mice/group) and C) females ( $\mathrm{n}=8-14$ mice/group). Weekly analysis of WT (black), Cre (green), Ak (blue), and Cre-Ak (red) male mice from the Akita/RIP-Cre F1 progeny, of: D) body weight ( $\mathrm{n}=6-9$ mice/group); E) non-fasting blood glucose ( $\mathrm{n}=6-9$ mice/group), using the Mixed Model Analysis for statistical significance; and F) diabetes incidence (defined as two consecutive weekly nonfasting blood glucose readings $\geq 300 \mathrm{mg} / \mathrm{dL}$ ), with pairwise comparisons using the Log-Rank (Mantel-Cox) Test for statistical analysis. ITT depicted as fold over time 0, in WT (black), PL (green), Ak (blue), and PLAk (red) mice from the Akita/RIP-mPL1 F1 progeny, in G) males ( $\mathrm{n}=6-7$ mice/group) and $\mathbf{H}$ ) females ( $\mathrm{n}=8-10$ mice/group); and AUC for the ITT in I) males and $\mathbf{J})$ females, using one-way ANOVA for 
statistical analysis. $\& \& \& \mathrm{p}<0.001, \& \& \& \& \mathrm{p}<0.0001$ versus WT and Cre. All error bars represent mean \pm SEM.

Supplemental Figure 2. $\beta$-cell homeostasis, insulin content, and in vitro GSIS of islets from RIPmPL1/Akita progeny. Analysis of WT (black), PL (green), Ak (blue), and PL-Ak (red) mice for: Pancreas weight at 12 weeks of age in $\mathbf{A}$ ) males ( $n=5-6$ mice/group) and $\mathbf{B}$ ) females ( $n=5-7$ mice/group); $\beta$-cell mass at 4 weeks of age in $\mathbf{C}$ ) males ( $n=4-5 /$ mice group) and $\mathbf{D}$ ) females ( $n=5$ mice/group); $\beta$-cell proliferation in males E) at 4 (n=4-5 mice/group) and F) 12 (n=5-6 mice/group) weeks of age, and females $\mathbf{G})$ at 4 ( $\mathrm{n}=4-5$ mice/group) and $\mathbf{H}) 12$ ( $\mathrm{n}=5-7$ mice/group) weeks of age; total insulin content per islet equivalent (IEQ) at 4 weeks of age in I) males ( $n=5-7$ mice/group) and $\mathbf{J}$ ) females ( $n=5-7$ mice/group); GSIS at 4 weeks of age in $\mathbf{K}$ ) males ( $\mathrm{n}=5-7$ mice/group) and $\mathbf{L}$ ) females ( $\mathrm{n}=5-7$ mice/group); insulin stimulation index at 4 weeks of age in $\mathbf{M}$ ) males and $\mathbf{N}$ ) females calculated as the ratio of insulin secretion at $22.2 \mathrm{mM}$ glucose/insulin secretion at $2.2 \mathrm{mM}$ glucose, from GSIS in $(\mathrm{K})$ and $(\mathrm{L})$, respectively. ${ }^{* *} \mathrm{p}<0.01$ versus $\mathrm{WT}$; \#\#p $<0.01$ versus $\mathrm{Ak} ; \$ \mathrm{p}<0.05$ versus other three groups; by one-way ANOVA. All error bars represent mean $\pm \mathrm{SEM}$.

\section{Supplemental Figure 3. ER stress pathway gene expression in INS1 cells and islets from RIP-} mPL1/Akita progeny. mRNA expression of ER stress genes measured by qRT-PCR in A) INS1 cells treated for $24 \mathrm{~h}+\mathrm{TM}(\mathrm{T})$ or DMSO (C), + PRL or vehicle (Veh), analyzing for protein folding chaperones (BiP, Grp94, protein disulfide isomerase) and components of the three ER-stress pathways (Txnip, Atf4, Atfo), relative to actin expression, and expressed as fold over control (Veh+C) $(n=4-5)$; in B-D) islets from 4wk old WT (black), PL (green), Ak (blue), and PL-Ak (red) female mice analyzing for the B) Perk (Perk, eIF2a, Chop $),$ C) Ire1 $\alpha(J n k 1, X b p 1)$, and D) Atf6 pathways, relative to Nkx6.1 expression, and expressed as fold over WT ( $\mathrm{n}=5-7$ /group). ${ }^{*} \mathrm{p}<0.05, * * \mathrm{p}<0.01, * * * \mathrm{p}<0.001$ versus Veh $+\mathrm{C}$ in INS1 cells by one-way ANOVA. All error bars represent mean \pm SEM. 
A Pancreas Weight (M, 12wks)

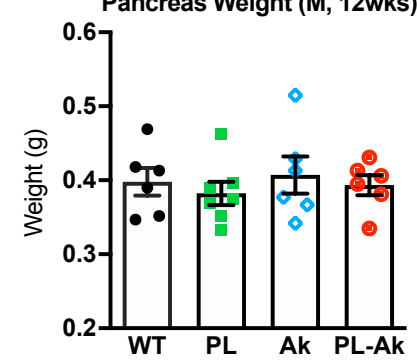

E

E $\beta$-cell Proliferation (M, 4wks)

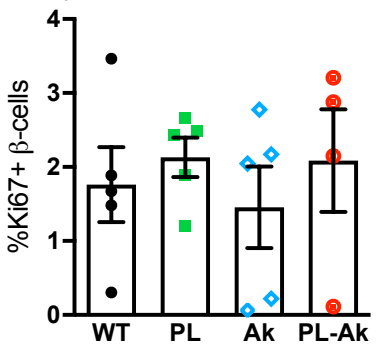

I

Total Insulin/IEQ (Males)

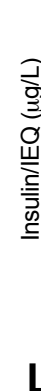

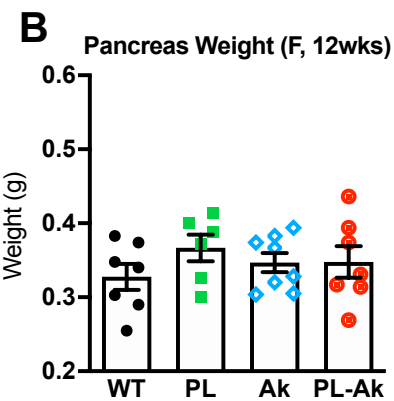

F $\beta$-cell Proliferation (M, 12wks)

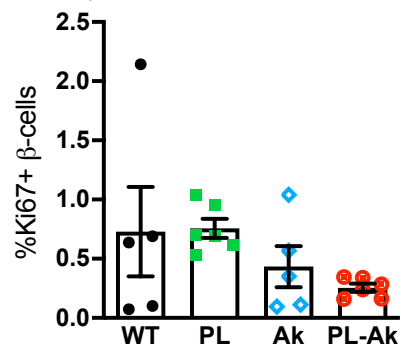

J Total Insulin/IEQ (Females)

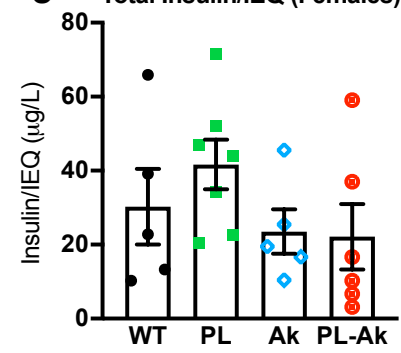

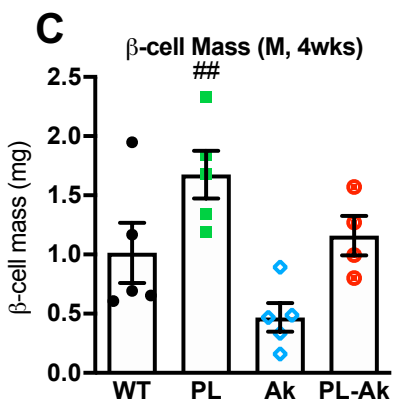

G $\beta$-cell Proliferation (F, 4wks)

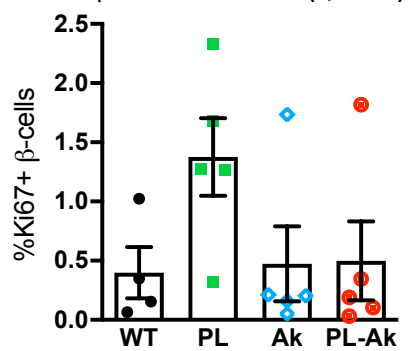

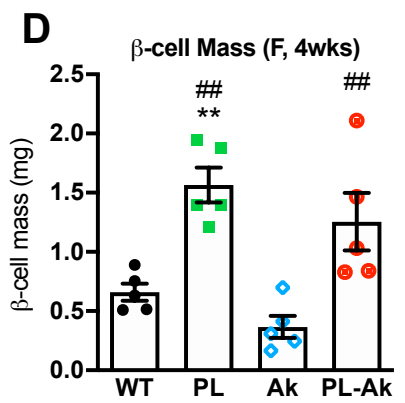

H

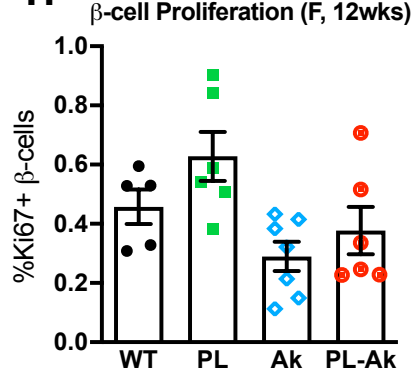

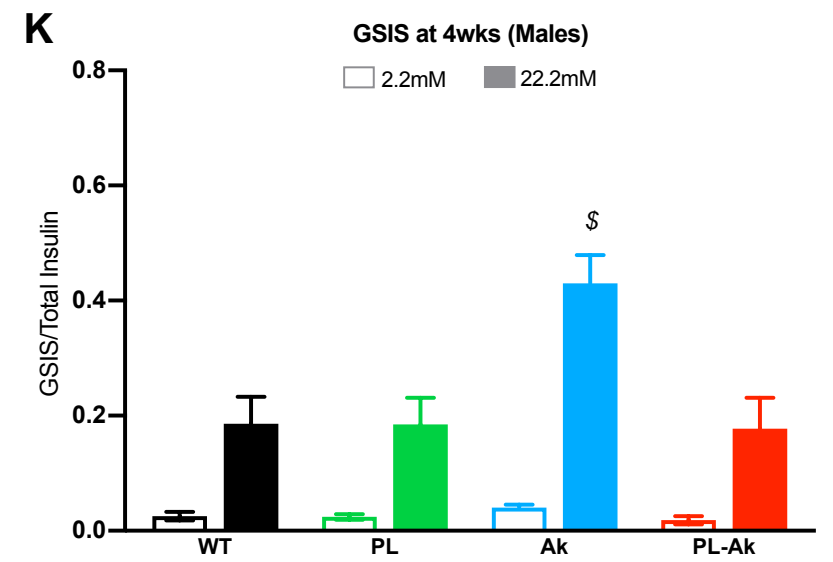

M
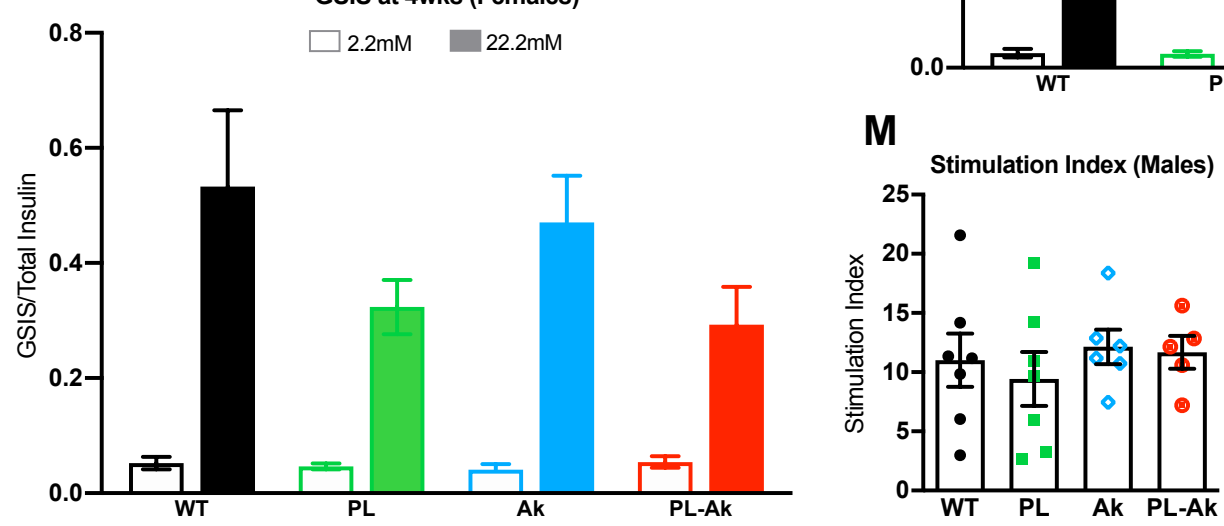

GSIS at 4wks (Females)

N

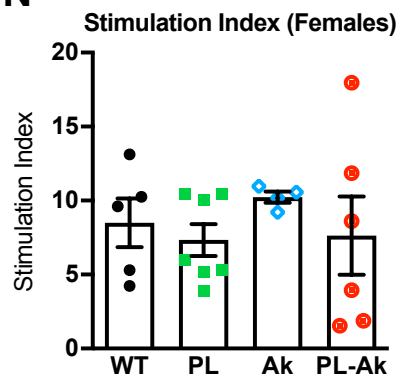




\section{Table 1. Human islet donor information}

\begin{tabular}{|c|c|c|c|c|c|}
\hline Islet Preparation & 1 & 2 & 3 & 4 & 5 \\
\hline Unique identifier & SAMN08769130 & SAMN08769390 & SAMN08769824 & SAMN08769830 & SAMN08930666 \\
\hline Donor Age (years) & 37 & 33 & 24 & 43 & 45 \\
\hline Donor Sex (M/F) & $M$ & $\mathrm{~F}$ & $\mathrm{~F}$ & $\mathrm{M}$ & $F$ \\
\hline Donor BMI $\left(\mathrm{kg} / \mathrm{m}^{2}\right)$ & 27.6 & 34.2 & 40.2 & 24.4 & 26.6 \\
\hline Donor HbA1c & 5.6 & 5.5 & 5.3 & 5.4 & 4.5 \\
\hline Origin/source of islets & IIDP & IIDP & IIDP & IIIDP & IIIDP \\
\hline Islet isolation center ${ }^{a}$ & $\begin{array}{l}\text { University of } \\
\text { Wisconsin }\end{array}$ & $\begin{array}{l}\text { University of } \\
\text { Wisconsin }\end{array}$ & $\begin{array}{l}\text { University of } \\
\text { Pennsylvania }\end{array}$ & $\begin{array}{l}\text { The Scharp-Lacy } \\
\text { Research } \\
\text { Institute } \\
\end{array}$ & $\begin{array}{l}\text { University of } \\
\text { Illinois }\end{array}$ \\
\hline Donor history of diabetes? Yes/No & No & No & No & No & No \\
\hline \multicolumn{6}{|l|}{$\begin{array}{l}\text { If Yes, complete the next two lines if this } \\
\text { information is available }\end{array}$} \\
\hline Diabetes duration (years) & Not Applicable & Not Applicable & Not Applicable & Not Applicable & Not Applicable \\
\hline Glucose-lowering therapy at time of death ${ }^{b}$ & Not Applicable & Not Applicable & Not Applicable & Not Applicable & Not Applicable \\
\hline Cause of death & $\begin{array}{l}\text { Cerebrovascular } \\
\text { /stroke }\end{array}$ & $\begin{array}{l}\text { Cerebrovascular } \\
\text { /stroke }\end{array}$ & Anoxia & Anoxia & $\begin{array}{l}\text { Cerebrovascular } \\
\text { /stroke }\end{array}$ \\
\hline Warm ischemia time $(\mathrm{h})$ & Not Reported & Not Reported & Not Reported & 0.8 & Not Reported \\
\hline Cold ischemia time $(\mathrm{h})$ & 11.3 & 14.3 & 12.3 & 11.2 & 7.8 \\
\hline $\begin{array}{l}\text { Estimated purity (\%) } \\
\text { By islet isolation center at time of } \\
\text { shipment with Dithizone (DTZ) staining per } \\
\text { IIDP SOP }\end{array}$ & 90 & 95 & 90 & 95 & 90 \\
\hline $\begin{array}{l}\text { Estimated viability (\%) } \\
\text { By islet isolation center at time of } \\
\text { broadcast with Fluorescence } \\
\text { Diacetate/Propidium lodide (FDA/PI) } \\
\text { staining per IIDP SOP }\end{array}$ & 98 & 98 & 92 & 95 & 97 \\
\hline $\begin{array}{l}\text { Total culture time }(\mathrm{h})^{\mathrm{c}} \\
\text { Calculate[start date/time of experiment]- } \\
\text { [date/time islet culture began (below)] }\end{array}$ & 64 & 90 & 56 & 75 & 89 \\
\hline $\begin{array}{l}\text { Date/Time Islet Culture Began at islet } \\
\text { isolation center (Pacific Standard Time, 24- } \\
\text { hour format) }\end{array}$ & 2016-09-18 16:00 & 2016-05-29 18:22 & $2016-02-2513: 15$ & $2016-02-0406: 20$ & 2016-01-04 04:00 \\
\hline $\begin{array}{l}\text { Glucose-stimulated insulin secretion or } \\
\text { other functional measurement }^{d} \\
\text { Stimulation Index (SI) by static incubation } \\
\text { at islet isolation center pre-shipment per } \\
\text { IIDP SOP }\end{array}$ & $\begin{array}{l}\mathrm{SI}(\mathrm{G} 2.8 \mathrm{mM}- \\
\mathrm{G} 28 \mathrm{mM})=2.2\end{array}$ & $\begin{array}{l}\mathrm{SI}(\mathrm{G} 2.8 \mathrm{mM}- \\
\mathrm{G} 28 \mathrm{mM})=1.6\end{array}$ & $\begin{array}{l}\mathrm{SI}(\mathrm{G} 2.8 \mathrm{mM}- \\
\mathrm{G} 28 \mathrm{mM})=2.3\end{array}$ & $\begin{array}{l}\mathrm{SI}(\mathrm{G} 2.8 \mathrm{mM}- \\
\mathrm{G} 28 \mathrm{mM})=3.6\end{array}$ & $\begin{array}{l}\mathrm{SI}(\mathrm{G} 2.8 \mathrm{mM}- \\
\mathrm{G} 28 \mathrm{mM})=1.2\end{array}$ \\
\hline $\begin{array}{l}\text { Glucose-stimulated insulin secretion or } \\
\text { other functional measurement } \\
\text { Area Under the Curve (AUC) by perifusion } \\
\text { at HIPP post shipment sample per HIPP SOP }\end{array}$ & $\begin{array}{l}\text { AUC }(\mathrm{G} 5.6 \mathrm{mM}- \\
\mathrm{G} 16.7 \mathrm{mM})=\text { Not } \\
\text { Available }\end{array}$ & $\begin{array}{l}\text { AUC }(\mathrm{G} 5.6 \mathrm{mM}- \\
\mathrm{G} 16.7 \mathrm{mM})=\mathrm{Not} \\
\text { Available }\end{array}$ & \begin{tabular}{|l|} 
AUC $(\mathrm{G} 5.6 \mathrm{mM}-$ \\
$\mathrm{G} 16.7 \mathrm{mM})=$ Not \\
Available
\end{tabular} & \begin{tabular}{|l|} 
AUC $(\mathrm{G} 5.6 \mathrm{mM}-$ \\
$\mathrm{G} 16.7 \mathrm{mM})=$ Not \\
Available
\end{tabular} & $\begin{array}{l}\text { AUC }(\mathrm{G} 5.6 \mathrm{mM}- \\
\mathrm{G} 16.7 \mathrm{mM})=\text { Not } \\
\text { Available }\end{array}$ \\
\hline Handpicked to purity? Yes/No & Yes & Yes & Yes & Yes & Yes \\
\hline Additional notes & Not Applicable & Not Applicable & Not Applicable & Not Applicable & Not Applicable \\
\hline
\end{tabular}




\section{Table 1. Human islet donor information}

\begin{tabular}{|c|c|c|c|c|c|}
\hline Islet Preparation & 6 & 7 & 8 & 9 & 10 \\
\hline Unique identifier & SAMN13067487 & SAMN13175912 & SAMN13254972 & SAMN13515839 & SAMN13938639 \\
\hline Donor Age (years) & 57 & 34 & 60 & 64 & 50 \\
\hline Donor Sex (M/F) & $M$ & $\mathrm{~F}$ & $\mathrm{~F}$ & $M$ & $\mathrm{~F}$ \\
\hline Donor BMI $\left(\mathrm{kg} / \mathrm{m}^{2}\right)$ & 21.3 & 30.3 & 44.4 & 20.9 & 39.2 \\
\hline Donor HbA1c & 4.9 & 4.8 & 5.6 & 5.5 & 5.0 \\
\hline Origin/source of islets & IIDP & IIDP & IIDP & IIDP & IIDP \\
\hline Islet isolation center ${ }^{a}$ & $\begin{array}{l}\text { University of } \\
\text { Miami }\end{array}$ & $\begin{array}{l}\text { University of } \\
\text { Pennsylvania }\end{array}$ & $\begin{array}{l}\text { University of } \\
\text { Wisconsin }\end{array}$ & \begin{tabular}{|l|} 
The Scharp-Lacy \\
Research \\
Institute
\end{tabular} & $\begin{array}{l}\text { Southern } \\
\text { California Islet } \\
\text { Cell Resource } \\
\text { Center }\end{array}$ \\
\hline Donor history of diabetes? Yes/No & No & No & No & No & No \\
\hline \multicolumn{6}{|l|}{$\begin{array}{l}\text { If Yes, complete the next two lines if this } \\
\text { information is available }\end{array}$} \\
\hline Diabetes duration (years) & Not Applicable & Not Applicable & Not Applicable & Not Applicable & Not Applicable \\
\hline Glucose-lowering therapy at time of death ${ }^{b}$ & Not Applicable & Not Applicable & Not Applicable & Not Applicable & Not Applicable \\
\hline Cause of death & $\begin{array}{l}\text { Cerebrovascular } \\
\text { /stroke }\end{array}$ & Anoxia & Head trauma & $\begin{array}{l}\text { Cerebrovascular } \\
\text { /stroke }\end{array}$ & $\begin{array}{l}\text { Cerebrovascular } \\
\text { /stroke }\end{array}$ \\
\hline Warm ischemia time $(\mathrm{h})$ & Not Reported & 0.5 & 0.3 & Not Reported & Not Reported \\
\hline Cold ischemia time (h) & 9.0 & 14.3 & 6.2 & 8.6 & 11.6 \\
\hline $\begin{array}{l}\text { Estimated purity (\%) } \\
\text { By islet isolation center at time of } \\
\text { shipment with Dithizone (DTZ) staining per } \\
\text { IIDP SOP }\end{array}$ & 90 & 95 & 97 & 95 & 80 \\
\hline $\begin{array}{l}\text { Estimated viability (\%) } \\
\text { By islet isolation center at time of } \\
\text { broadcast with Fluorescence } \\
\text { Diacetate/Propidium lodide (FDA/PI) } \\
\text { staining per IIDP SOP }\end{array}$ & 90 & 93 & 98 & 95 & 95 \\
\hline $\begin{array}{l}\text { Total culture time }(\mathrm{h})^{c} \\
\text { Calculate[start date/time of experiment]- } \\
\text { [date/ time islet culture began (below)] }\end{array}$ & 72 & 24 & 24 & 24 & 24 \\
\hline $\begin{array}{l}\text { Date/Time Islet Culture Began at islet } \\
\text { isolation center (Pacific Standard Time, 24- } \\
\text { hour format) }\end{array}$ & 2019-10-17 11:30 & 2019-10-30 19:00 & 2019-11-10 17:00 & 2019-12-08 14:00 & $2020-01-2801: 30$ \\
\hline $\begin{array}{l}\text { Glucose-stimulated insulin secretion or } \\
\text { other functional measurement }^{\mathrm{d}} \\
\text { Stimulation Index (SI) by static incubation } \\
\text { at islet isolation center pre-shipment per } \\
\text { IIDP SOP }\end{array}$ & $\begin{array}{l}\mathrm{SI}(\mathrm{G} 2.8 \mathrm{mM}- \\
\mathrm{G} 28 \mathrm{mM})=2.2\end{array}$ & $\begin{array}{l}\mathrm{SI}(\mathrm{G} 2.8 \mathrm{mM}- \\
\mathrm{G} 28 \mathrm{mM})=1.4\end{array}$ & $\begin{array}{l}\mathrm{SI}(\mathrm{G} 2.8 \mathrm{mM}- \\
\mathrm{G} 28 \mathrm{mM})=2.3\end{array}$ & $\begin{array}{l}\mathrm{SI}(\mathrm{G} 2.8 \mathrm{mM}- \\
\mathrm{G} 28 \mathrm{mM})=3.6\end{array}$ & $\begin{array}{l}\mathrm{SI}(\mathrm{G} 2.8 \mathrm{mM}- \\
\mathrm{G} 28 \mathrm{mM})=1.2\end{array}$ \\
\hline $\begin{array}{l}\text { Glucose-stimulated insulin secretion or } \\
\text { other functional measurement } \\
\text { Area Under the Curve (AUC) by perifusion } \\
\text { at HIPP post shipment sample per HIPP SOP }\end{array}$ & $\begin{array}{l}\text { AUC (G5.6mM- } \\
\text { G16.7mM) }=21.2 \\
\text { (ng/100 IEQs) }\end{array}$ & $\begin{array}{l}\text { AUC }(\mathrm{G} 5.6 \mathrm{mM}- \\
\text { G16.7mM })=\text { Not } \\
\text { Available }\end{array}$ & $\begin{array}{l}\text { AUC (G5.6mM- } \\
\text { G16.7mM) }=10.0 \\
\text { (ng/100 IEQs) }\end{array}$ & $\begin{array}{l}\text { AUC (G5.6mM- } \\
\text { G16.7mM)= } 24.8 \\
(\mathrm{ng} / 100 \text { IEQs) }\end{array}$ & $\begin{array}{l}\text { AUC }(\mathrm{G} 5.6 \mathrm{mM}- \\
\mathrm{G} 16.7 \mathrm{mM})=0.0 \\
\text { (ng/100 IEQs) }\end{array}$ \\
\hline Handpicked to purity? Yes/No & Yes & Yes & Yes & Yes & Yes \\
\hline Additional notes & Not Applicable & Not Applicable & Not Applicable & Not Applicable & Not Applicable \\
\hline
\end{tabular}


Table 1. Human islet donor information

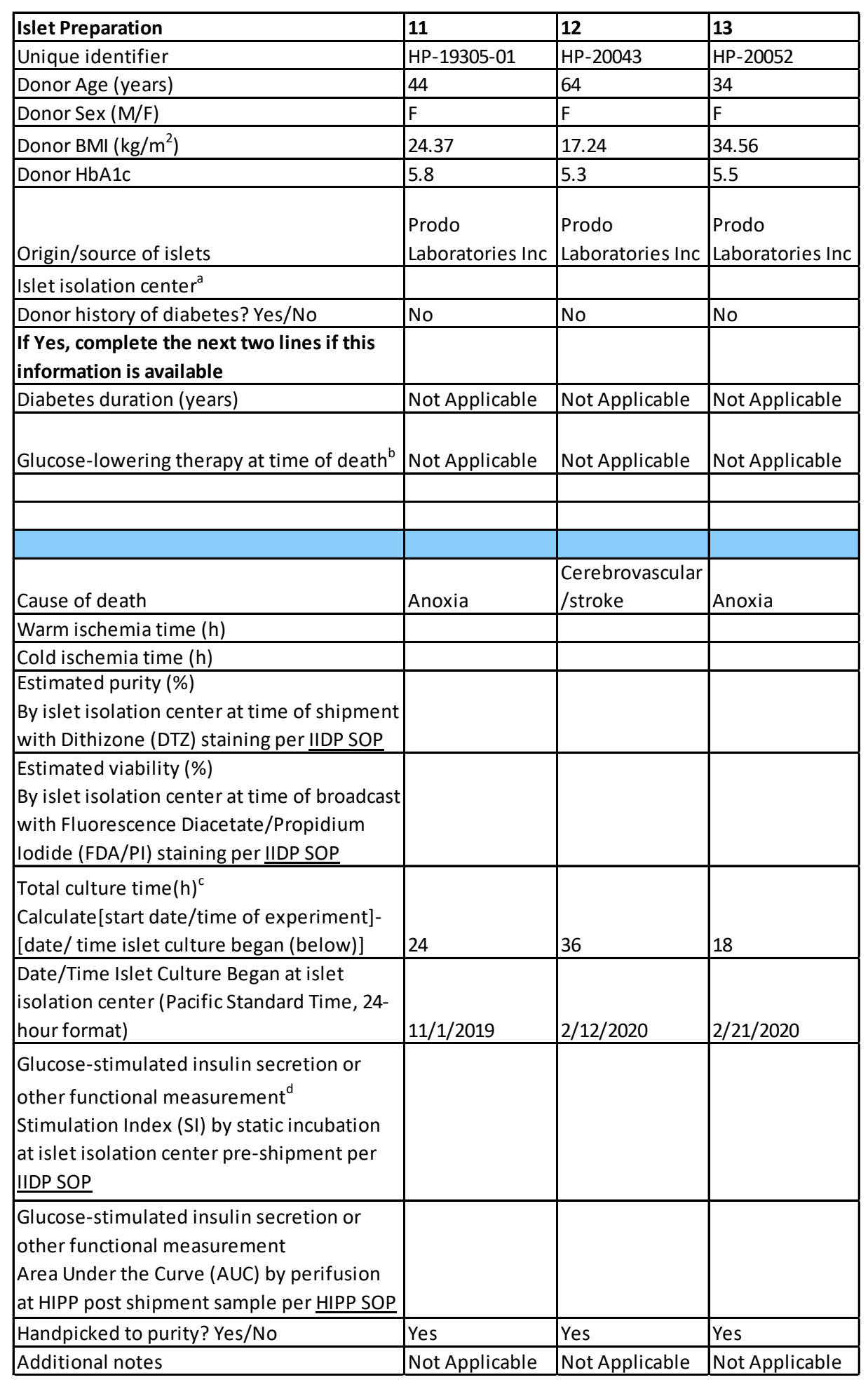




\section{Table 2. Antibodies and GSIS reagents}

\begin{tabular}{|c|c|c|c|c|}
\hline \multicolumn{2}{|r|}{ Reagent } & Company & Catalog \# & Dilution \\
\hline \multicolumn{2}{|r|}{ Rabbit $\boldsymbol{\alpha}$-Cleaved Caspase-3 } & Cell Signaling Technology & 9661 & $1: 200$ \\
\hline \multicolumn{2}{|r|}{ Guinea Pig $\alpha$-Insulin } & DAKO (Agilent) & A0564 & $1: 1000$ \\
\hline \multicolumn{2}{|r|}{ Rabbit $\boldsymbol{\alpha}-\mathrm{Ki} 67$} & ThermoFisher Scientific & RM-9106-S1 & $1: 200$ \\
\hline \multicolumn{2}{|r|}{ Rabbit $\boldsymbol{\alpha}$ - $\boldsymbol{\beta}$-actin } & Sigma-Millipore & SAB5500001 & $1: 2000$ \\
\hline \multicolumn{2}{|r|}{ Mouse $\boldsymbol{\alpha}$-PRLR } & Invitrogen & $35-9200$ & $1: 1000$ \\
\hline \multicolumn{2}{|r|}{ Mouse $\boldsymbol{\alpha}$-CHOP (L63F7) } & Cell Signaling Technology & 2895 & $1: 100$ \\
\hline \multicolumn{2}{|r|}{ Alexa Fluor 488 Goat $\boldsymbol{\alpha}$-Rabbit } & Life Technologies & A11034 & $1: 200$ \\
\hline \multicolumn{2}{|r|}{ Alexa Fluor 594 Goat $\boldsymbol{\alpha}$-Guinea Pig } & Life Technologies & A11076 & $1: 200$ \\
\hline \multicolumn{2}{|r|}{ Alex Fluor 594 Goat $\boldsymbol{\alpha}$-Rabbit } & Life Technologies & A11037 & $1: 200$ \\
\hline \multicolumn{2}{|r|}{ Alexa Fluor 488 Goat $\alpha$-Guinea Pig } & Life Technologies & A11073 & $1: 200$ \\
\hline \multicolumn{2}{|r|}{ Alexa Fluor 488 Goat $\alpha$-Mouse } & Life Technologies & A11029 & $1: 250$ \\
\hline \multicolumn{2}{|r|}{ HRP Donkey $\boldsymbol{\alpha}$-Guinea Pig } & Jackson ImmunoResearch & $706-035-148$ & $1: 500$ \\
\hline \multicolumn{2}{|r|}{ HRP Goat $\boldsymbol{\alpha}$-Rabbit } & Abcam & ab7090 & $1: 5000$ \\
\hline \multicolumn{2}{|r|}{ HRP Goat $\alpha$-Mouse } & Abcam & ab97040 & $1: 5000$ \\
\hline \multicolumn{2}{|c|}{ DAPI (4',6-Diamidino-2-Phenylindole, Dilactate) } & Life Technologies & D3571 & $1: 1000$ \\
\hline \multicolumn{2}{|r|}{ DAB Peroxidase Substrate Kit } & Vector Labs & SK 4100 & \\
\hline \multicolumn{2}{|r|}{ DeadEnd Fluorometric TUNEL Kit } & Promega & G3250 & \\
\hline \multirow{8}{*}{$\begin{array}{l}\text { KREBS } \\
\text { Buffer }\end{array}$} & Sodium chloride ( $\mathrm{NaCl} 129 \mathrm{mM})$ & Sigma & S7653 & \\
\hline & Potassium chloride $(\mathrm{KCl} 4.8 \mathrm{mM})$ & Sigma & P9333 & \\
\hline & $\begin{array}{c}\text { Calcium chloride dihydrous }\left(\mathrm{CaCl}_{2} 2 \mathrm{H}_{2} \mathrm{O}\right. \\
2 \mathrm{mM})\end{array}$ & Sigma & C1016 & \\
\hline & Sodium bicarbonate $\left(\mathrm{NaHCO}_{3} 24 \mathrm{mM}\right)$ & Sigma & S5761 & \\
\hline & $\begin{array}{c}\text { Potassium dihydrogen phosphate } \\
\left(\mathrm{KH}_{2} \mathrm{PO}_{4} 1.2 \mathrm{mM}\right)\end{array}$ & Sigma & 10487 & \\
\hline & $\begin{array}{l}\text { Magnesium sulfate heptahydrate } \\
\left(\mathrm{Mg}_{2} \mathrm{SO}_{4} 7 \mathrm{H}_{2} \mathrm{O} 1.2 \mathrm{mM}\right)\end{array}$ & Sigma & 1374361 & \\
\hline & HEPES $(6 \mathrm{mM})$ & Corning & $25-060-\mathrm{Cl}$ & \\
\hline & $\mathrm{BSA}(0.2 \%)$ & Gemini & $700-100 \mathrm{P}$ & \\
\hline \multirow{2}{*}{$\begin{array}{c}5 \% \text { acid- } \\
\text { ethanol }\end{array}$} & Acetic acid & Sigma & A6283 & \\
\hline & Ethanol & Decon & 2701 & \\
\hline
\end{tabular}




\section{Table 3. Primer sequences for genotyping and qRT-PCR}

\begin{tabular}{|c|c|c|}
\hline \multicolumn{3}{|c|}{ Mouse Primers } \\
\hline Gene & Sequence & Expected Size \\
\hline \multirow{2}{*}{$\mathrm{mPL} 1$} & F: 5' CTA CGG GCT GCT CTA CTG CTT CAG G 3' & \multirow{2}{*}{$\begin{array}{c}\text { Between } 1008 \\
200 \mathrm{bp}\end{array}$} \\
\hline & R: 5' GGC ACT GGA GTG GCA ACT TCC AAG G 3' & \\
\hline \multirow{2}{*}{ GAPDH } & F: 5' CGT GGA GTC TAC TGG TGT CTT CAC C 3' & \multirow{2}{*}{$259 b p$} \\
\hline & R: 5' GAT GGC ATG GAC TGT GGT CAT GAG C 3' & \\
\hline \multirow{2}{*}{ Akita } & F: 5'TGC TGA TGC CCT GGC CTG CT 3' & \multirow{2}{*}{$\begin{array}{l}\text { WT 140bp } \\
\text { HT 280bp }\end{array}$} \\
\hline & R: 5' TGG TCC CAC ATA TGC ACA TG 3' & \\
\hline \multicolumn{3}{|c|}{ Rat Primers (Mouse Compatible) } \\
\hline \multirow{2}{*}{$\beta$-actin } & \multicolumn{2}{|l|}{ F: 5' CAA CCT TCT TGC AGC TCC TC 3' } \\
\hline & \multicolumn{2}{|l|}{ R: 5' TTC TGA CCC ATA CCC ACC AT 3' } \\
\hline \multirow{2}{*}{ Cyclophilin A } & \multicolumn{2}{|l|}{ F: 5' AGC CAC TCA GTC TTG GCA GT 3' } \\
\hline & \multicolumn{2}{|l|}{ R: 5' AGC ACT GGG GAG AAA GGA TT 3' } \\
\hline \multirow{2}{*}{ Atf4 } & \multicolumn{2}{|l|}{ F: 5' GTT GGT CAG TGC CTC AGA GA 3' } \\
\hline & \multicolumn{2}{|l|}{ R: 5' CAT TGC AAA CAG AGC ATC GA 3' } \\
\hline \multirow{2}{*}{ Atf6 } & \multicolumn{2}{|l|}{ F: 5' GGT TGT CAC CAT CTG ACG TG 3' } \\
\hline & \multicolumn{2}{|l|}{ R: 5' CAG AGG CTC AAA GTC CCA AG 3' } \\
\hline \multirow{2}{*}{$\mathrm{BiP}(\mathrm{Grp} 78)$} & \multicolumn{2}{|l|}{ F: 5' CCA CCA GGA TGC AGA CAT TG 3' } \\
\hline & \multicolumn{2}{|l|}{ R: 5' AGG GCC TCC ACT TCC ATA GA 3' } \\
\hline \multirow{2}{*}{ Chop } & \multicolumn{2}{|l|}{ F: 5' TCT CAT CCC CAG GAA ACG AA 3' } \\
\hline & \multicolumn{2}{|l|}{ R: 5' ATC TGG AGA GCG AGG GCT TT 3' } \\
\hline & F: 5' AAT GCC CTC CTT CAT GTC AG 3' & \\
\hline elF2a & R: 5' TTG TGT TTG GAG TCC CTG GT 3' & \\
\hline Grno4 & F: 5' TCG GGA AGC AAC AGA GAA G 3' & \\
\hline Grp94 & R: 5' TCA TCT TCC TTA ACC CTC CG 3' & \\
\hline Ino1 & F: 5' GTT TGC TCT TGG CCT CTG TC 3' & \\
\hline ireia & R: 5' GCG ATG GAC TGG TGG TAA CT 3' & \\
\hline $\ln k 1$ & F: 5' CGG AAC ACC TTG TCC TGA AT 3' & \\
\hline $\mathrm{JnK}_{1}$ & R: 5' TCG CCT GAC TGG CTT TAA GT 3' & \\
\hline Perk & F: 5' TTG GGC TAG TGA CTG CAA TG 3' & \\
\hline Perk & R: 5' TTG TCC CGT GTG TGT AGC AT 3' & \\
\hline Pdi & F: 5' AAG AAC CTG GAA CCC AAG TA 3' & \\
\hline Pdi & R: 5' TGG TAG GAA AAC CCT TGA CT 3' & \\
\hline Tynin & F: 5' CTG ATG GAG GCA CAG TGA GA 3' & \\
\hline Ixnip & R: 5' CTC GGG TGG AGT GCT TAG AG 3' & \\
\hline & F: 5' AAA GGG AGG CTG GTA AGG AA 3' & \\
\hline Xbp1 & R: 5' ATT CTG ACG CTG TTG CCT CT 3' & \\
\hline lak? & F: 5' GCATTCCTGATTTGCT 3' & \\
\hline 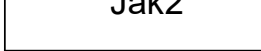 & R: 5' CCCTGCAGTCTGCCTTCTAC 3' & \\
\hline & Human Primers & \\
\hline & F: 5' CAT GTA CGT TGC TAT CCA GGC 3' & \\
\hline$\beta$-actin & R: 5' 3'CTC CTT AAT GTC ACG CAC GAT 3' & \\
\hline hPRIR & F: 5' ACCAGCAGGTGAATGTTTCC 3' & \\
\hline MIRKLR & R: 5' TCCTATTCATGGAGGCGAAC 3' & \\
\hline
\end{tabular}

